Association for Information Systems

AIS Electronic Library (AISeL)

\title{
Prominence-for-data schemes in digital platform ecosystems: Economic implications for platform bias and consumer data collection
}

\author{
Marc Bourreau \\ Télécom ParisTech \\ Janina Hofmann \\ Universität Passau \\ Jan Krämer \\ Universität Passau
}

Bourreau, Marc; Hofmann, Janina; and Krämer, Jan, "Prominence-for-data schemes in digital platform ecosystems: Economic implications for platform bias and consumer data collection" (2021). Wirtschaftsinformatik 2021 Proceedings. 1.

https://aisel.aisnet.org/wi2021/GFuture18/Track18/1

This material is brought to you by the Wirtschaftsinformatik at AIS Electronic Library (AISeL). It has been accepted for inclusion in Wirtschaftsinformatik 2021 Proceedings by an authorized administrator of AIS Electronic Library (AISeL). For more information, please contact elibrary@aisnet.org. 


\title{
Prominence-for-data schemes in digital platform ecosystems: Economic implications for platform bias and consumer data collection
}

\author{
Marc Bourreau ${ }^{1}$, Janina Hofmann ${ }^{2}$, Jan Krämer ${ }^{2}$ \\ ${ }^{1}$ Telecom ParisTech, Department of Economics and Social Sciences, Paris, France \\ marc.bourreau@telecom-paristech.fr \\ ${ }^{2}$ University of Passau, School of Business, Economics and Information Systems, Passau, \\ Germany \\ janina.hofmann@uni-passau.de,jan.kraemer@uni-passau.de
}

\begin{abstract}
.
It is crucial for content providers (CPs) to appear prominently on dominant online platforms in order to attract consumer demand. Apart from organic search results, content providers can obtain such prominence also in return for a monetary payment to the platform, e.g., in the form of sponsored search results. In this article, we investigate some of the economic consequences, if such payment can also be made with consumers' data instead of money. Since data is non-rivalrous, the economic effects of data sharing for prominence are more complex and differ from paying for prominence. In a game-theoretic model we show that more consumer data will be collected as soon as CPs can obtain prominence on the platform. Whether the platform is more biased under a prominence-for-money scheme or under a prominence-for-data scheme depends on the marginal value of shared (non-exclusive) data. If this value is high, prominence-for-data will yield a higher platform bias, lead to more data collection by the CPs, and ultimately lower consumer surplus. Our results therefore bear important insights for the regulation of data-rich online platforms.
\end{abstract}

Keywords: B2B data sharing, prominence on platforms, consumer data, data collection

\section{Introduction}

The European Commission recognizes online platforms as the "key gatekeepers of the internet" (European Commission, 2017, p. 7). For instance, $82 \%$ of small and medium enterprises (SMEs) state in a survey realized by the European Commission that they are reliant on search engines in order to favor their offered services and products (European Commission, 2017). The main purpose of online platforms is to organize and present the available content in a way that facilitates the consumers' discovery process for content (Krämer \& Schnurr, 2018; Renda, 2015). However, this also implies 
that online platforms have the ability to steer consumers towards a specific content provider (CP) by giving that $\mathrm{CP}$ more prominence on the platform. Prominence is commonly granted in return for monetary payments to the platform (e.g., sponsored search results), usually elicited in the course of a position auction. However, platforms have also been accused to extract data from CPs (e.g., on consumer behavior), which helps them to optimize their business and to increase their data-induced market power. Often platforms induce CPs to share some of their data by offering them benefits on the platform or through access to some additional services (e.g., a social login or fulfillment service). In this paper, we specifically consider the scenario where a $\mathrm{CP}$ is offered more prominence on the platform (e.g. by biasing the search results in favor of that $\mathrm{CP}$ ) in return for access to the CP's data.

This scenario is exemplified by Google's accelerated mobile pages (AMP) project, whose main purpose is to speed up mobile websites by hosting the content directly on Google's services. However, this also has the (likely intended) effect that Google is able to attain the usage statistics of unaffiliated websites that are accessed via AMP. In return, AMP-enabled websites are placed more prominently in the mobile search results, e.g. by showing in the so-called carousel results or simply be being listed higher in the mobile search results page (because they load faster). Thus, in effect, AMP is a means to implement data for prominence (Jun et al., 2019).

This relatively new phenomenon of business-to-business (B2B) data sharing as an alternative currency for CPs to gain prominence on online platforms has not been considered in the economic literature so far, despite its practical and political relevance. B2B data sharing reveals certain characteristics and implications which differ strongly from monetary payment. Most importantly, data is non-rivalrous which means that it can be duplicated effortlessly. This implies that the welfare effects of payments in data are far more complex since welfare is not simply shifted from the sender to the recipient of the payment.

\section{Related literature}

We contribute to the emerging literature on digital platform ecosystems, which is reviewed more generally by De Reuver et al. (2018) as well as Hein et al. (2020). More specifically, we consider how the value generated by data is distributed between the platform and the complementors (see Tiwana (2015)) for a review. Our paper especially contributes to two literature branches - payment for prominence and data-driven markets.

First, payment for prominence on online platforms has previously been considered in various contexts - i.e. usability, welfare effects and policy regulations. Receiving prominence on platforms is crucial for content providers to obtain consumer demand (Krämer \& Zierke, 2020). For instance, Ursu (2018) shows that a higher ranking and thus, more prominence significantly increases the consumers' click through rates. Krämer and Schnurr (2018) review the literature concerning both the strategic and the 
welfare effects of paying for prominence in order to investigate whether there is a need for a platform neutrality regulation. On the one hand, if CPs compete in prices, sponsored search on rankings results in increased prices and thus, a lower consumer surplus. Although the platform's and the CPs' profits increases, the CPs may end up in a prisoners' dilemma and hence, the total welfare is likely to be smaller under payment for prominence (Armstrong \& Zhou, 2011; Zhou, 2011). On the other hand, if CPs compete in qualities, content providers which offer a higher quality also have an higher willingness-to-pay for prominence on the platform and hence, prominence serves as signals for the CPs' content quality and increases the consumer surplus and the total welfare (Athey \& Ellison, 2011; Chen \& He, 2011; de Cornière \& Taylor, 2020; Krämer and Zierke, 2020). Therefore, consumers are not necessarily worse off under a prominence for data scheme. In particular, De Cornière and Taylor (2019) study the effects of biased intermediation for a, with the platform, integrated CP. Depending on whether the seller's and the consumers' payoffs are conflicting or congruent, a bias can be beneficial for consumers.

Second, several theoretical papers model competition in data-driven markets. For instance, Prüfer and Schottmüller (2017) analyze under which conditions duopolies are stable and when monopolies emerge in data-driven markets. De Cornière and Taylor (2020) examine under which conditions a firm with a better (worse) data set generates more (less) consumer utility in data-driven mergers or consumers privacy concerns regarding data disclosure. Gu et al. (2019) as well as Ichihashi (2019) model competition of data intermediaries explicitly. One of their main findings is that the economic profits of a firm are the greater, the more data is exclusively available to that firm. We built on their results and take these findings as input for our model. De Cornière and de Nijs (2016) analyze the impact of disclosing consumer information on product prices. In their model an online platform decides whether to give advertisers access to the platform's consumer information prior bidding on the platform's advertising slots but before learning the consumers' information. While there is a burgeoning literature on digital platforms, payment-for-prominence, and data-driven markets, respectively, to the best of our knowledge, the economic impacts of prominence-for-data schemes have not been studied in the literature so far.

\section{$3 \quad$ Model}

We develop a game-theoretic model in order to analyze the economic implications of data-for-prominence schemes in the platform economy. In our model, a monopolistic platform can decide to offer one of two CPs more prominence on the platform (e.g., by biasing the search results) in return for a share of the CP's data. The platform can steer consumers to one of the two CPs by giving it prominence on the platform, e.g., by ranking it systematically higher in the search results everything else being equal. In this case, we will say that the platform has a 'bias'.

Both CPs compete for the consumers' attention, and they offer their content for free, but collect data from the users that consume their content. 
The consumers single-home and after entering the platform, they choose which of the two CPs they want to visit. The consumer demand of each CP depends on three main factors. Everything else being equal, consumers prefer the CP which (1) collects less data about them, and (2) which offers content that is closer to the consumer's individual preference; but (3) the CP's demand depends also on the platform's bias.

Moreover, the CPs compete with the platform on the data market (e.g., the market for targeted advertising, selling data analytics services or simply as a data broker) in which they can exploit the consumer data acquired by offering their consumer-facing service. While we abstract from modelling competition in the data market explicitly, we borrow the central insight from explicit models of competition data intermediaries (Gu et al., 2019; Ichihashi, 2019) that the economic profits of a firm are the greater, the more of the firm's data is exclusively available to that firm. The platform and the CPs can reap higher profits in the data market, the more user data they possess. However, due to the non-rivalry of data, competition in the data market intensifies as more firms possess the same data sets. This enables us to examine the trade-offs the CPs face when sharing data in return for prominence, what impact the substitutability of the acquired data has on data sharing and the welfare effects.

We compare three scenarios. First, a baseline scenario where the platform can choose to bias the presentation in favor of one of the CPs, but does not receive a compensation in money or data in return. Second, a prominence-for-data scheme, where the platform offers to bias the presentation in favor of one CP in return for a share of that CP's data. Third, a counterfactual prominence-for-money scheme, where the platform offers to bias the presentation in return for a financial payment, but where the platform does not receive additional data from the $\mathrm{CP}$.

We analyze the scenarios by backwards induction in order to determine the subgameperfect equilibria. Thereby, the timing is as follows: In Stage 1, the platform chooses a prominence offer by selecting a level of bias and, depending on the scenario, a compensation in terms of data or money. In Stage 2, the CPs decide whether to accept the prominence offer. In Stage 3, the CPs choose their data collection level, and in Stage 4 , the consumers decide which $\mathrm{CP}$ to access and demands are realized.

\section{$4 \quad$ Findings}

We find that the platform has no incentive to bias the presentation in favor of one $\mathrm{CP}$, if it does not receive a compensation in return. An unbiased platform maintains the highest possible level of competition for consumers between the CPs, and induces the CPs to limit the amount of data that they collect from consumers. On the one hand, this is good for the platform itself, especially if the platform has already access to large consumer data sets, because it avoids that CPs can collect more data on consumers themselves, which would lower the average value of the platform's data set. On the other hand, an unbiased platform also preserves consumers' privacy in the best possible way, and avoids that some consumers may be steered away from the content that would 
offer them the highest utility. Therefore, an unbiased platform always provides the highest possible consumer surplus.

Introducing a bias would weaken the competition between CPs and allow them to collect more data from consumers. This in turn, intensifies the competition with the platform on the data market.

However, we can also show that if the platform can be compensated for giving prominence to a $\mathrm{CP}$, either through a prominence-for-money or prominence-for-data scheme, then this provides the platform with additional incentives to introduce a bias. The bias can either be higher under a prominence-for-money scheme or a prominencefor-data scheme, depending in the marginal value of non-exclusive data.

If the value of shared (non-exclusive) data is low, the platform has a larger incentive to bias under a prominence-for-money scheme, and will also make larger profits under this scheme. However, if the marginal value of shared data is high, then a prominencefor-data scheme leads to a higher platform bias, and a higher platform profit. However, for consumers a larger platform bias is always welfare decreasing, because it weakens the competition between CPs, and leads to collection of more data, and hence higher privacy costs for consumers.

\section{References}

1. Armstrong, M., Zhou, J.: Paying for prominence. In: The Economic Journal, issue 556, vol. 121, pp. F368-F395. (2011)

2. Athey, S., Ellison, G.: Position auctions with consumer search. In: Quarterly Journal of Economics, issue 3, vol. 126, pp. 1213-1270. (2011)

3. Chen, Y., He, C.: Paid placement: Advertising and search on the internet. In: The Economic Journal, issue 556, vol. 121, pp. F309-F328. (2011)

4. De Cornière, A., De Nijs, R. (2016). Online advertising and privacy. In: The RAND Journal of Economics, issue 1, vol. 47, pp. 48-72. (2016)

5. De Cornière, A., Taylor, G.: A model of biased intermediation. In: The RAND Journal of Economics, issue 4, vol. 50, pp. 854-882. (2019)

6. De Cornière, A., Taylor, G.: Data and Competition: A General Framework with Applications to Mergers, Market Structure, and Privacy Policy. In: CEPR Discussion Paper, DP14446 (2020)

7. De Reuver, M., Sørensen, C., Basole, R. C.: The digital platform: a research agenda. In: Journal of Information Technology, issue 2, vol. 33, pp. 124-135. (2018)

8. European Commission: Communication from the commission on the mid-term review on the implementation of the digital single market strategy: A Connected Digital Single Market for All. $\operatorname{COM}(2017)$ 228, European Commission (2017)

9. Gu, Y., Madio, L., Reggiani, C.: Data brokers co-opetition. Working paper (2020)

10. Hein, A., Schreieck, M., Riasanow, T., Setzke, D. S., Wiesche, M., Böhm, M., \& Krcmar, H.: Digital platform ecosystems. In: Electron Markets, vol. 30, pp. 87-89. (2020)

11. Ichihashi, S.: Non-competing data intermediaries. Working paper (2019)

12. Jun, B., Bustamante, F. E., Whang, S. Y., Bischof, Z. S.: AMP up your Mobile Web Experience: Characterizing the Impact of Google's Accelerated Mobile Project. In: The 25th Annual International Conference on Mobile Computing and Networking. pp. 1-14. (2019)

13. Krämer J., Zierke O.: Paying for Prominence: The Effect of Sponsored Rankings on the Incentives to Invest in the Quality of Free Content on Dominant Online Platforms (2020) 
14. Krämer, J., \& Schnurr, D.: Is there a need for platform neutrality regulation in the EU?. In: Telecommunications Policy, vol. 42, pp. 514-529. (2018)

15. Prüfer, J., Schottmüller, C.: Competing with Big Data. In: TILEC Discussion Paper, vol. 2017-006, CentER Discussion Paper, vol. 2017-007. (2017)

16. Renda: Antitrust, regulation and the neutrality trap: A plea for a smart, evidence-based internet policy. (2015)

17. Tiwana, A.: Evolutionary competition in platform ecosystems. In: Information Systems Research, vol. 26, pp. 266-281. (2015)

18. Ursu, R. M., Aryotejo,G., Mufadhol, M.: The power of rankings: Quantifying the effect of rankings on online consumer search and purchase decisions. In: Marketing Science, vol. 37, pp. 530-552. (2018)

19. Zhou, J.: Ordered search in differentiated markets. In: International Journal of Industrial Organization 2, vol. 29, pp. 253-262. (2011) 